\title{
REDES COLABORATIVAS, ÉTICA HACKER E EDUCAÇÃO
}

\section{Nelson Pretto*}

RESUMO: O texto discute as transformações do mundo contemporâneo a partir da presença intensa de tecnologias digitais de informação e comunicação. Analisa o que denominamos de labirinto espaço-temporal, constituidor da hipertextualidade do mundo contemporâneo. Parte da compreensão das tecnologias digitais para discutir as novas linguagens e a sua apropriação pela juventude. Analisa a produção do conhecimento em função do movimento global de produção colaborativa de conhecimento livre com base na denominada ética hacker para, pensar a educação numa perspectiva colaborativa. Destaca o papel da cultura digital enquanto espaço aberto no qual os novos modos de relacionamento e de intercâmbio de culturas promovem, potencialmente, novas possibilidades de produção de conhecimentos e culturas. Propõe ao final, considerar a educação com base na pluralidade construindo novas educações.

Palavras-chave: Conhecimento Livre; P2P; Ética Hacker; Educação; Produção Colaborativa.

\section{COLLABORATIVE PRODUCTION, HACKER ETHIC AND EDUCATION}

ABSTRACT: The paper focuses on the transformations of the contemporary world with the intense presence of digital information and communication technologies. It analyses what we call space-time labyrinth which characterizes the contemporary hypertextuality of the world. Based on an understanding of digital technologies, we discuss the languages associated with it and its appropriation by the youth. We analyze the production of knowledge considering the global movement of free and collaborative production of knowledge through digital technologies, based on the so-called hacker ethic. We also think about education from a collaborative perspective, emphasizing the role of digital culture as an open place for new modes of relationships and exchange of cultures, promoting new possibilities for the production of knowledge and cultures. Finally, we propose to consider education from a plurality view for the construction of new forms of education.

Keywords: Free Knowledge; Peer-To-Peer; Hacker Ethic; Education; Collaborative Production.

\footnotetext{
* Doutor em Ciências da Comunicação pela Universidade de São Paulo (USP); Professor associado III da Faculdade de Educação da Universidade Federal da Bahia (UFBA) e Pesquisador do Conselho Nacional de Desenvolvimento Científico e Tecnológico (CNPq). E-mail: nelson@pretto.info
} 
"Cara, eu botei lá a parada, você não está me prejudicando, você está me ajudando, bota lá, baixa a parada"

BNegão

\section{Rede: nova maneira de produzir conhecimento}

A evolução científica e tecnológica das duas últimas décadas mudou qualitativamente as relações humanas, a sociabilidade e a relação entre as sociedades. $\mathrm{O}$ aumento do ritmo das transformações conduziu, nos seus limites, ao achatamento do tempo e à contração do espaço, um possibilitando o outro, reciprocamente, constituindo-se em um verdadeiro labirinto espaço-temporal. Presente, passado e futuro, em relação ao tempo, e local e não-local, em relação ao espaço (HARVEY, 1992; AUGE, 1994), concretamente, perdem nitidez e fundem-se por meio de aparatos tecnológicos digitais que são estruturantes de uma hipertextualidade. Hipertextualidade esta que vai além da comunicação, como afirmou Pierre Lévy, em As tecnologias da Inteligência. Para ele, "os processos sociotécnicos, sobretudo, também têm uma forma hipertextual, assim como vários outros fenômenos. O hipertexto é talvez uma metáfora válida para todas as esferas em que significações estejam em jogo" (LÉVY, 1993, p. 25). Hipertexto passou a ser conceito fundante a partir do trabalho de Theodor Nelson, na década de 60 do século passado. A proposta original de Vannevar Bush de criação de um grande mecanismo de amplificação da memória, com o estabelecimento de links variados, apareceu pela primeira vez em um artigo publicado na revista americana The Atlantic Monthly, descrevendo o sistema Memex (Memory Extension, extensão da memória). "A memex is a device in which an individual stores all his books, records, and communications, and which is mechanized so that it may be consulted with exceeding speed and flexibility. It is an enlarged intimate supplement to his memory" (THE ATLANTIC MONTLY, 1945).

No entanto, é bom lembrar que essas primeiras ideias estavam ainda baseadas em tecnologias muito simples se comparadas com as que hoje temos disponíveis. Com o desenvolvimento da computação, ao longo da segunda metade do século passado, foram sendo incorporados novos elementos tecnológicos que ampliaram a compreensão sobre o hipertexto, com a ampliação das possibilidades de criação de links a partir do texto que relacionam, de forma imediata, elementos textuais outros 
distribuídos no ciberespaço. São as conexões por meio dos nós que articulam textos escritos, imagens, sons, simulações ou animações e que possibilitam pensar numa relação mais intensa entre aquilo que é posto - o real - e o que está em potência.

Configura-se, assim, um verdadeiro labirinto, com inúmeras possibilidades que serão vivenciadas a partir do caminhar, ou do navegar, ou do estar à toa na rede. Da metáfora inicial usada para significar a utilização da internet (navegar) chegamos a esse à toa, do caminhar sem compromisso (to browse), como sugeriu Sérgio Costa, no III Encontro Nacional sobre Hipertexto, em 2009. As primeiras inspirações da relação que estabelecíamos com o ciberespaço levava-nos à figura do "navegar é preciso", utilizada por Fernando Pessoa. E, já naquele período, alertávamos para a necessidade de pensar a palavra "preciso" no referido verso, não associando-a à precisão, à exatidão. Passamos, portanto, do "navegar é preciso" ao "navegar não é preciso" e, hoje, ao andar descompromissadamente pela rede mundial de computadores, captando daqui e dali fragmentos que vão construindo o todo a partir desses movimentos em torno dos links oferecidos e dos criados pelos internautas. Os movimentos se dão, portanto, pelos labirintos das redes ou, como afirma Maria Helena Dias,

infinitas portas vão se abrindo no sentido de se aprofundar ou se ampliar conhecimentos sobre determinado tema à semelhança de um labirinto que se abre em novas salas e estas, por sua vez, conduzem a passagens que se abrem em outras, à semelhança, também, de um contador de histórias ou uma Princesa Sherazade que se dispõem a "contar outra" a cada "link" (interconexão ou nexo) ou palavra motivadora (DIAS, 2000, s/p).

No entanto, inúmeras vezes percebemos que essas possibilidades não são consideradas, porque o uso dessas tecnologias não considera as transformações contemporâneas e insiste em incorporá-las aos processos, principalmente no campo da educação, tentando encaixá-las em concepções que as aprisionam em grades conceituais que não possibilitam o caminhar mais solto e mais amplo, característico da hipertextualidade e da cibercultura. O que temos percebido é que, na maioria das vezes, as tecnologias digitais - e a internet, em particular - são tratadas como meras ferramentas auxiliares dos processos educacionais.

Analisando de que forma se dava o uso das tecnologias nas universidades, com foco na televisão e no vídeo, Pretto (1996) já afirmava ser 
necessário pensá-las numa perspectiva outra que não a meramente instrumental. Necessário se faz, nesse contexto, pensar as "novas" tecnologias digitais, e a internet em particular, enquanto algo para além dessa perspectiva ferramental, considerando-a, como afirma Mark Poster, como um "espaço social”, acrescentamos, caracterizada pela hipertextualidade. O que isso significa e quais os seus efeitos? Mark Poster:

[os seus efeitos são] mais como os da Alemanha do que como os dos martelos. Os efeitos da Alemanha sobre as pessoas dentro dela é o de torná-los alemães (pelo menos na maior parte dos casos); os efeitos do martelo não é fazer com que as pessoas sejam martelos, embora os Heideggerianos e alguns outros possam discordar, mas pregar pontas metálicas na madeira. Enquanto entendermos a [i]nternet como um martelo, vamos deixar de compreendê-la como compreendemos o exemplo da Alemanha. O problema é que as perspectivas modernas tendem a reduzir a [i]nternet à um martelo. Na grande narrativa da modernidade, a [i]nternet é uma ferramenta eficaz de comunicação, que adianta os objetivos de seus usuários, entendidos como pré-constituídos de identidades instrumentais (POSTER, 2001, p. 177, grifo nosso).

Para Mark Poster (e para nós), a internet e o conjunto de tecnologias digitais são muito mais do que essa "ferramenta eficaz de comunicação". E isso pudemos observar ao longo dos anos, acompanhando o desenvolvimento tecnológico e sua apropriação pela sociedade.Essa perspectiva para além da ferramenta pode ser evidenciada em vários exemplos e aqui destacaremos apenas um.

No início do ano 2000, quando os primeiros aparelhos celulares foram apresentados à sociedade, ficava evidente sua função de ser mais um meio de distribuição (instrumental) de informações, como o anúncio de cotações da bolsa de valores, oferta de produtos para compras e noticiário em geral, tudo, como de costume, gerado pelos grandes grupos de mídia e distribuído por meio daqueles primeiros equipamentos móveis.

Nossa crítica, à época, concentrava-se no fato de que aqueles primeiros equipamentos continham, basicamente, a funcionalidade de recebimento de informações, constituindo-se, junto com a própria internet, em verdadeiros "portais-currais" (LEMOS, 2000; PRETTO, 2000). Desde aquele momento, consideramos importante criticar essa perspectiva de uso das tecnologias e, em particular, na educação, que consideravam (ou consideram?!) necessários esses portais para organizar as informações para os professores, como se eles fossem incapazes de navegar na inter- 
net sem a existência de bússolas orientadoras ou, quem sabe, fios de Ariadne que possibilitassem única e exclusivamente a chamada navegação segura. Impossível pensar no "browsear". Impossível pensar no labirinto. O labirinto, aqui, amedrontava (amedronta?!). E, com isso, não se configurariam as redes de relações colaborativas e, muito menos, a possibilidade de considerar a pluralidade de olhar dos sujeitos interagentes.

Ocorre que, daqueles primeiros momentos desse século até hoje, o que aconteceu foi que a juventude apropriou-se das tecnologias e as transformou completamente, de um meio meramente receptor de informações para um meio de expressão de ideias e de manifestação da pluralidade e de cidadania.

No caso daqueles aparelhos celulares, eles passaram a ser usados como elementos estruturantes de outra comunicação, alimentando, no ato, em tempo real, sítios como o Twitter, Identica, Orkut, Flickr, Myspace, Facebook, entre outros.

Mas isso não está se dando somente com a juventude, e muito menos apenas para uma juventude privilegiada economicamente. Os dados sobre o uso da telefonia móvel no Brasil e no mundo indicam claramente um crescimento espantoso de acesso a essa rede. No caso do Brasil, os números de 2008 apontam que o país já possuía mais de 128 milhões de linhas instaladas ${ }^{1}$. Em termos mundiais, em 1991, existiam 34 linhas de telefone fixo para cada móvel e, em 2004, as assinaturas de telefones móveis superavam os fixos ("1.748 milhões de celulares/1.198 milhões de telefones fixos”) (LEADBEATER, 2009, p. 185). Com o acesso facilitado, seu uso extrapola o juvenil, passando a serem usados por todas as idades, como pode ser visto nos recentes exemplos nos movimentos em defesa das liberdades no Irã, quando praticamente toda a mobilização ocorrida foi postada pelos ativistas e militantes iranianos com textos, imagens, vídeos e áudios, de lá para o mundo, sem passar pelos tradicionais canais de comunicação.

Essa apropriação traz, associadas a ela, transformações na forma de se manifestar. Exemplo dos mais significativos nos dias de hoje é o Twitter. Aqui, o que temos são novas formas de expressão e linguagens, já que essa plataforma de comunicação limita a escrita ao máximo de 140 caracteres, o que demanda não só a utilização de expressões abreviadas, já típicas da escrita da juventude nos SMS (short message service - serviço de mensagens curtas), mas também outras formas de expressão, mais sintéticas e mais diretas. 
Como afirmou Sérgio Costa, no Hipertexto 2009, ele permite "a construção de novos gêneros de texto, em que o nomadismo e as relações entre superfície e interface estão presentes. Trata-se da chamada 'cultura móvel', em que o nomadismo é uma de suas características principais, com sua instabilidade, heterogeneidade e fluidez, refletidas nas práticas comunicativas ciberespaciais".

Complementarmente, como a ideia básica é dizer o que se está fazendo para aqueles que são interessados no seu dia a dia, cria-se um efeito multiplicador significativo, com o denominado efeito Twitter, significando uma expansão exponencial da rede assim formada.

Nesse contexto, é importante compreender como a presença das tecnologias digitais, denominadas por Pierre Lévy de tecnologias da inteligência (LÉVY, 1993), e que Luis Felippe Serpa denomina de tecnologias proposicionais (SERPA, 2004), passam a operar em uma dimensão diferente das antigas tecnologias, que operavam numa perspectiva de extensão dos sentidos do homem.

Hoje, passamos a ter um conjunto de tecnologias que não mais operam na perspectiva de amplificar os sentidos, mas que passam a operar com as ideias propriamente ditas. Em outras palavras, máquinas que não mais estão apenas (apenas?!) a serviço do homem, mas que com ele interagem, formando um conjunto homem-máquina pleno de significado. De acordo com o físico inglês Stephen Wolfram, citado por Piere Lévy,

a mudança é ainda mais fundamental, pois surgiu um novo modo de pensamento científico. Doravante, as leis científicas são consideradas como algoritmos e mitos desses algoritmos são estruturados por computadores; por outro lado, consideram-se os sistemas físicos como sistemas informáticos que processam a informação à maneira dos computadores (LÉVY, 1998, p. 114).

\section{A produção colaborativa}

A ideia de produção colaborativa e compartilhada ganhou destaque no final do século passado, a partir do desenvolvimento da computação e com os movimentos do software livre e do código aberto. Para este texto, é importante retomar o início do desenvolvimento da ciência da computação, já referido quando lembramos de Vannevar Bush e Theodor Nelson. 
$\mathrm{Na}$ mesma segunda metade do século passado, jovens estudantes, interessados no desenvolvimento tecnológico e nas mudanças do mundo, começaram a desenhar programas e máquinas a partir de uma nova linguagem que começava a ser escrita. Era o nascimento da linguagem binária, que possibilita o digital. Essa turma de jovens estudantes ocupava garagens, porões e laboratórios das universidades americanas, particularmente no MIT (Instituto de Tecnologia de Massachusetts) e, com ou sem seus professores, começaram a desenvolver os primeiros computadores pessoais e suas engenhocas.

Boa parte desses movimentos tinha como princípio uma intensa lógica de partilhamento, inerente à própria cultura daqueles que passaram a ser conhecidos como hackers. O processo de produção desses novos aparatos tinha como metodologia resolver os problemas surgidos em cada um dos projetos e, a cada solução, a imediata circulação dela para ser objeto de crítica dos outros. Era o início do até hoje conhecido RFC (Request For Comments - solicitação de comentários), comum na computação, que nada mais é do que pôr uma ideia (uma solução) na mesa, aguardando a colaboração dos demais.

Steven Levy (2001), analisando os heróis da revolução dos computadores, resgata o código de ética criado pelos primeiros hackers, reunidos em torno dos clubes juvenis no MIT, no final da década de 50 do século passado. Esses grupos articulavam-se nas universidades para ocupar espaços dos laboratórios e, com isso, trabalhar no desenvolvimento de protótipos tecnológicos, em paralelo ao seu processo de formação em nível superior. Essa juventude, que se reunia para comer comida chinesa e desvendar os mistérios dos primeiros e enormes equipamentos informáticos (LEVY, 2001), acreditava que, para o bom desenvolvimento desses clubes e de seus projetos, seis princípios deveriam presidir todo o trabalho desses apaixonados pela computação e pela criação. Primeiro, pensar que o acesso aos computadores deveria ser total e ilimitado. Mais do que computadores, deveria ser liberado o acesso a "qualquer coisa que pudesse ensinar a você alguma coisa sobre como o mundo funciona" (LEVY, 2001, p. 40). Segundo, que toda informação deve ser livre (free), porque "se você não tem acesso à mesma, não terá como consertar as coisas” (p. 40). Aqui é importante lembrar que, em inglês, a palavra free pode tanto significar livre quanto grátis, o que nos permite considerar que toda informação deve ser livre e gratuita. O terceiro princípio indica que 
se deve sempre desconfiar da autoridade e, assim, estimulam-se procedimentos pouco burocráticos, com liberdade de circulação de informações e acesso a elas por qualquer um. A descentralização passa a ser a palavra de ordem. O julgamento dos hackers deve ser feito pela qualidade do que eles efetivamente fazem e realizam, afirmam em seu quarto princípio, e não por critérios falsos, como escolaridade, idade, raça ou posição. Confrontando a dureza aparente das máquinas, o quinto princípio defende que "é possível criar arte e beleza num computador" (p. 43). Por último, e não menos importante, acredita-se que os computadores podem fazer a vida melhor. Foi com esse conjunto de elementos éticos que os hackers trabalharam (e isso nos inspira a pensar nas necessárias transformações na educação!) de forma coletiva e aberta, criando os computadores, expandindo as redes de computadores e promovendo o nascimento da internet.

Sobre essa ética hacker, outro autor também dedicou boa parte de suas pesquisas, trazendo importante contribuição para a discussão da sociedade contemporânea. Pekka Himanen, em A Ética Hacker (2001), descreve os métodos de trabalho daqueles que atuam mais diretamente no desenvolvimento de softwares para computadores e, expandindo esse conceito, pensa que essa postura hacker pode ser, em última instância, uma postura para todos os campos das atividades humanas.

Para Himanen, são sete as características da chamada ética dos hackers: paixão, liberdade, valor social (abertura), nética (ética da rede), atividade, participação responsável e criatividade, todas elas devendo estar presentes nos três principais aspectos da vida: trabalho, dinheiro e ética da rede (HIMANEN, 2001, p. 125-127).

Esses princípios dos hackers possibilitaram a construção do ciberespaço, que, com os aparatos tecnológicos digitais, possibilitou intrinsecamente a emergência de novas linguagens e de novas práticas de produção de conhecimentos e de culturas. Destacam-se, nesse campo, as redes ponto a ponto (peer-to-peer: rede entre pares, rede entre amigos, $\mathrm{p} 2 \mathrm{p}$ ), que têm como base a produção e a circulação colaborativa, que partilha as produções e os conhecimentos.

$\mathrm{O}$ início desse movimento seguramente pode ser associado às trocas de arquivos pela internet através de pioneiros programas como o Naspter e com a possibilidade de compressão de arquivos de música a partir do algoritmo de compressão (proprietário) que ficou conhecido 
como mp3. Essas redes distribuídas, não-hierárquicas e descentralizadas, nas quais cada usuário, ou seja, cada computador na rede pode, ao mesmo tempo, exercer a função de cliente e servidor e, o mais importante, sem um gerenciamento central, faz com que a informação trafegue velozmente, possibilitando múltiplas conexões simultâneas.

Esses movimentos para o desenvolvimento dos softwares livres catalizaram um conjunto de outros movimentos, que aqui não vamos focalizar, ligados aos licenciamentos de produtos científicos, acadêmicos e culturais, gerando as licenças abertas, como a General Public License (GPL), o Copyleft e o Creative Commons. Esse conjunto de ações concomitantes foi fortalecendo uma cultura de partilhamento, cultura essa básica e fundamental para a educação.

\section{A cultura hacker na educação}

Em todo o mundo há uma enorme demanda por mudanças na educação, uma vez que, na dinâmica social contemporânea, transformações já vêm ocorrendo, o que sugere a necessidade urgente de se desenvolver outras estratégias para se pensar a educação contemporaneamente.

A escola, nesse contexto, especialmente a pública, ganha especial destaque enquanto espaço físico tecnologicamente equipado para se constituir em uma verdadeira plataforma de integração e articulação da juventude. Essas escolas, esses espaços singulares, promovendo interações entre os sujeitos, entre si e com as tecnologias, promovem a convivência dos múltiplos contextos e das múltiplas subjetividades inerentes à espécie humana, configuram-se tanto como lugares específicos quanto como possibilidades de conexões com outros lugares, estes também específicos, promovendo outros entrelugares, fruto dessas relações singulares. Estes, por sua vez,

são instáveis, pois decorrem da ressonância do diálogo de dois lugares, que ressaltam na precipitação de acontecimentos produzidos pelo diálogo [dos diferentes, acrescento]; ao terminar a ressonância, o entre-lugar se esvai, mas os dois lugares que precipitam os acontecimentos ressonantes agregam conhecimento (SERPA, 2004, p. 166). 
A rede estabelece-se. Fortalece-se.

Para que isso se configure, precisamos afastar a ideia de uma escola única, padronizada, concebida de fora para ser seguida em processos de reprodução indefinida. Pensamos, portanto, em pedagogia da diferença, conforme já apresentamos em outros textos (PRETTO; SERPA, 2001; SERPA, 2004). Pedagogias que tenham na hipertextualidade, possibilitada pela cibercultura, o fortalecimento de uma rede não-linear de diferenças. As transformações necessárias apontam para um ritual de passagem da porta da sala de aula que represente o fortalecimento do "eu" e a aprendizagem da convivência com a diferença. Assim, quando essas diferenças existirem e formarem parte viva dos processos, perderá sentido a porta da sala de aula, uma vez que, através das redes e conexões, o diferente estará interagindo com o de dentro e com o de fora, instantânea e constantemente. $\mathrm{O}$ que vai importar será exatamente esse movimento de interação e troca.

Interação e troca entre sujeitos. Interação e troca entre produtos culturais. Recombinagem. Remixagem. Nova produção e diálogo permanente com o instituído, produzindo-se, a partir daí, novos produtos, novas culturas e novos conhecimentos. Tudo no plural. Com isso, temos a possibilidade de retomar o papel de liderança acadêmica do professor, que, em conjunto com os alunos, no coletivo e individualmente, passam a interagir de forma intensa com esse labirinto de possibilidades.

A revolução tecnológica das duas últimas décadas, como já mencionamos, possibilita e exige pedagogias que desenvolvam a (con)vivência entre os diferentes, interpenetrando local - não-local e passado-presentefuturo. Nesse processo de convivência, o que se busca é não apenas a sua consideração como elemento inicial e ilustrador dos processos de transformação do diferente no igual, mas, sim, o próprio enaltecimento das diferenças.

Infelizmente, ainda hoje, sobe a égide da escola, desenvolvem-se pedagogias da assimilação, isto é, processos educativos que transformam o "outro" no "eu", estando o diferente apenas como elemento ilustrador inicial desses processos de transformação. A entrada da internet e das tecnologias digitais na escola, portanto, termina, paradoxalmente, por configurar-se como um elemento estranho ao corpo da escola. Paradoxalmente porque, para a juventude, essa relação com a tecnologia se dá de forma quase transparente. Assim, insistindo-se na implantação de pedagogias de 
assimilação nas escolas e nos sistemas educativos, a escola tornar-se-á, seguramente, dispensável, inútil e empobrecida.

Necessário se faz, para concluir o texto sem encerrar o debate, retomar o caráter das tecnologias digitais: local-não-local e passado-presente-futuro interpenetrando-se em uma topologia de vizinhanças das interações humanas. Dessa forma, pensamos ser possível, considerando a ética hacker que nos alimenta, a construção de outras educações, com base na pluralidade como parte integrante dos processos. Também para as palavras necessitamos desse plural. Portanto, em vez de educação, falamos em educações, com esse plural pleno, implicando todas e todos num rico processo de criação permanente. Como afirma Felippe Serpa, "no plano da não hegemonia, necessita-se de uma nova educação, radicalmente distinta da educação da modernidade, baseada na escola única. No limite extremo, cada grupo humano desenvolveria a sua educação" (SERPA, 2004, p. 156 ).

Como BNegão afirmou na citação que abre este artigo, pensamos em escolas produzindo de forma aberta culturas e conhecimentos, circulando as criações humanas de forma intensa, sem intermediários, a partir da generosidade e da colaboração, algo bastante distinto do que hoje estamos acostumados a ver.

Essa escola, repleta de processos criativos, com sua inserção no ciberespaço, afasta, na prática, a ideia de uma escola distribuidora de informações, verticalizadas e produzidas de forma centralizada, em que aos estudantes só resta a opção de consumir. 


\section{Referências}

AUGÉ, Marc. Não-lugares: introdução a uma antropologia da supermodernidade. São Paulo: Papirus, 1994.

COSTA, Sérgio. Cibridismo, hibridização, nomadismos e produção/recepção de gênero de texto do/no discurso cibercultural. Palestra em mesa-redonda no III Encontro Nacional sobre Hipertexto, Belo Horizonte, CEFET-MG, out. 2009 (notas).

DIAS, Maria Helena. Hipertexto - o labirinto eletrônico: uma experiência hipertextual. Tese (Doutorado em Educação), Unicamp, 2000. Disponível em: <http://www.unicamp.br/ $\sim$ hans/mh>. Acessado em 14 nov. 2009.

HARVEY, David. Condição pós-moderna: uma pesquisa sobre as origens da mudança cultural. São Paulo: Loyola, 1996.

HIMANEN, Pekka. A ética dos Hacker. São Paulo: Campus/Elsevier, 2001.

LEADBEATER, Charlie. We-think: the power of mass creativity. London: Profile, 2007. LEMOS, André. Morte aos portais-currais, Pilula. Disponível em: < http://www.facom.ufba.br/ ciberpesquisa/andrelemos/portais.html>. Acessado em 12 nov. 2001.

LÉVY, Pierre. As tecnologias da inteligência. São Paulo: 34, 1993.

LÉVY, Pierre. A máquina universo: cognição e cultura informática. Porto Alegre: Artmed, 1998. LEVY, Steven. Hackers: heroes of the computer revolution. Dell Publishing Co., 2001.

PRETTO, Nelson De Luca. Linguagens e Tecnologias na Educação. Rio de Janeiro, X ENDIPE - Encontro Nacional de Didática e Prática de Ensino, Anais..., maio 2000.

PRETTO, Nelson De Luca. Escritos sobre Educação, Comunicação e Cultura. Campinas: Papirus, 2008.

PRETTO, Nelson De Luca; SILVEIRA, Sérgio Amadeu. (Org.). Além das redes de comunicação: internet, diversidade cultural e tecnologias do poder. Salvador: Edufba, 2008.

PRETTTO, N.; SERPA, L. F. A Educação e a Sociedade da Informação. In: DIAS, P.; FREITAS, C. V. (Org). Actas da II Conferência Internacional das TIC na Educação: Challenges 2001. Braga: Centro de Competência Nónio Século XXI. 21-41, 2001.

SERPA, Luis Felippe P. Rascunho digital: diálogos com Felippe Serpa. Salvador: Edufba, 2004. THE ATLANTIC MONTHLY. As We May Think, jul. 1945. Disponível em <http://www.theatlantic.com/doc/194507/bush>. Acessado em 12 nov. 2009.

\section{Nota}

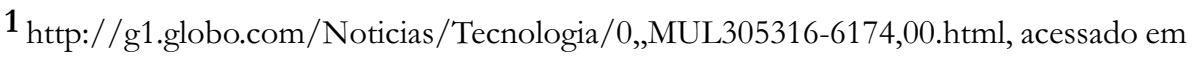
12.11.2009.

Recebido: $21 / 11 / 2009$

Aprovado: $17 / 08 / 2010$

Contato:

Universidade Federal da Bahia

Faculdade de Educação - Departamento de Educação II

Av. Reitor Miguel Calmon, $\mathrm{s} / \mathrm{n} \cdot 3^{\circ}$ andar

Canela

Salvador - BA

CEP 40110-100 